\title{
Alimentos microencapsulados para el cultivo de larvas de pejelagarto (Atractosteus tropicus)
}

Miguel Saenz de Rodrigáñez ${ }^{1}$, Federico Vladymir Aguilar-Tellez ${ }^{2}$, Francisco Javier Alarcón-López ${ }^{3}$, Ruth Pedrosa-Islas ${ }^{4}$, Emyr Saul Peña-Marín ${ }^{2,5}$, Rafael Martínez-García ${ }^{2}$, Rocío Guerrero-Zárate ${ }^{2}$, Wilfredo A. Matamoros ${ }^{1}$

\& Carlos Alfonso Álvarez-González ${ }^{*}$

1. Colección de Ictiología, Instituto de Ciencias Biológicas, Universidad de Ciencias y Artes de Chiapas. México. CP. 29039. Tuxtla Gutiérrez, Chiapas, México; miguel.saenz@unicach.mx; wilmatamoros@yahoo.com

2. Laboratorio de Acuicultura Tropical, DACBiol-UJAT. Carretera Villahermosa-Cárdenas km 0.5, Villahermosa, Tabasco.86039. México; f-vladimir1@hotmail.com; biologomartinez@hotmail.com; rocio7224@hotmail.com; alvarez_alfonso@hotmail.com

3. Departamento de Biología Aplicada, La Cañada de San Urbano, Universidad de Almería, Almería. 04120. España; falcarcon@ual.es

4. Departamento de Ingeniería Química, Industrial y de Alimentos. Universidad Iberoamericana. D.F., México. C P. 01219, México; rth.pdrz@gmail.com

5. Cátedra-Consejo Nacional de Ciencia y Tecnología-UJAT. México City, México. C.P. 03940; ocemyr@yahoo.com.mx * Correspondencia

Recibido 14-VI-2018. Corregido 22-VI-2018. Aceptado 02-VII-2018.

\begin{abstract}
Microencapsulated diets for tropical gar (Atractosteus tropicus) larviculture. Tropical gar is an important species for aquaculture purposes in Southeast Mexico. Several studies regarding nutrition and digestive physiology have been done; however, the use of microcapsules for larvae feeding to improve growth and survival has not been conducted. In this sense, four microencapsulated diets were evaluated with respect to the growth and survival of tropical gar Atractosteus tropicus larvae. The treatments consisted of four experimental diets and one control diet 1) fish meal, 2) a combination of pork and poultry meals, 3) Nannochloropsis gaditana meal, 4) enzyme preparation and the control treatment 5) Artemia nauplii. The evaluation indicated that the larvae fed the Artemia nauplii obtained the greatest growth and survival ( $3.93 \mathrm{~cm}, 0.19 \mathrm{~g}$ y $82 \%$ respectively), which justifies a correct culture system operation. While larvae fed microencapsulated diets best values in survival were observed with diets Nannochloropsis gaditana and enzyme preparation (20.0 and 19.2\%). Our results showed that microencapsulated could be used to feed $A$. tropicus in feasibly form. However, more information concerning to optimize the design and manufacturing are required to improve the growth and survival of organisms. Rev. Biol. Trop. 66(3): 1298-1313. Epub 2018 September 01.
\end{abstract}

Key words: aquaculture; growth; larvae; microencapsulated diets; survival.

En los últimos años, el sureste mexicano ha denominado al sector de la acuicultura como un posible motor para la economía de la zona, haciendo de las nuevas especies autóctonas de peces dulceacuícolas el foco de los estudios para la diversificación en el sector. Dentro de todas ellas, encontramos el pejelagarto (Atractosteus tropicus Gill, 1863), que ha despertado el interés del sector acuícola gracias a su carne blanca, firme y muy apreciada en la zona. Como cualquier especie, que quiera ser adaptada para su cultivo, se encuentra con diferentes problemas tales como, la creación de bancos de reproductores, la inducción a puesta y el larvicultivo, características fundamentales para la obtención de semillas en gran cantidad para su posterior engorda y así, a largo plazo, asegurar un aporte constante de juveniles con 
miras a potenciar su cultivo a escala comercial (Marquez-Couturier, Váquez-Navarrete, Contreras-Sánchez, \& Álvarez-González, 2015). Hasta la fecha, los trabajos de investigación en esta especie se han centrado en el requerimiento nutricional y los estudios para el desarrollo de alimentos balanceados a partir del conocimiento de la fisiología digestiva de larvas y juveniles (Frías-Quintana, Álvarez-González, \& Márquez-Couturier, 2010; Guerrero-Zárate et al., 2014; Frías-Quintana et al., 2015, Frías-Quintana, Domínguez-Lorenzo, ÁlvarezGonzález, Tovar-Ramírez, \& Martínez-García, 2016). A pesar del esfuerzo realizado, la larvicultura, todavía presenta problemas asociadas al canibalismo y cierto rechazo hacia el alimento artificial, una vez que se inicia el periodo de deshabituación al alimento vivo (nauplios de Artemia), por lo que se requiere utilizar las presas vivas por lo menos 15 días a partir de la apertura de la boca (Márquez-Couturier et al., 2006).

En este aspecto, el uso de este alimento vivo si bien proporciona mayores tasas de supervivencia y crecimiento en los primeros estadios de desarrollo, tiene ciertos inconvenientes, ya puede actuar como vector de enfermedades, su valor nutricional es variable y su producción es costosa, por lo que encarece el cultivo de larvas (Hart \& Purser, 1996; Ribeiro, Engrola, \& Dinis, 2005; Walker \& Mohan, 2009). Añadido a esto, la gran demanda de Artemia y las condiciones del principal productor donde se cultiva (Gran Lago Salado, USA), hacen que los costos de los quistes de alta calidad sean muy variable (Lavens \& Sorgeloos, 2000). En este sentido, en la cría larvaria de $A$. tropicus, es interesante desarrollar alternativas que permitan disminuir el uso de presas vivas en esta etapa.

De esta forma, se ha realizado, con relativo éxito, la adaptación al consumo de alimento artificial, evaluando su crecimiento y supervivencia (Márquez-Couturier et al., 2006; Márquez-Couturier, Vázquez-Navarrete, Contreras-Sánchez, \& Alvarez-González, 2015; Álvarez-González, Márquez-Couturier, Contreras-Sánchez, \& Rodríguez-Valencia,
2007) incluso se han diseñado y evaluado diferentes dietas micropartículadas basándose en la capacidad digestiva in vitro de larvas, analizando el grado de hidrólisis y liberación de aminoácidos totales (Frías-Quintana et al., 2010), pero en estos casos, son piensos molidos y tamizados para ajustarse al tamaño de la boca del pez, que en definitiva, son poco estables en agua, aumentando la perdida de nutrientes por lixiviación lo cual provocan un deterioro de la calidad del medio de cultivo (Cahu \& Zambonino-Infante, 2001).

En los últimos años, se han evaluado diferentes tipos de micropartículas, tanto simples como complejas, con el fin de la vehiculización de nutrientes en las etapas iniciales del cultivo de peces (Langdon, Levine, \& Jones, 1985; Yúfera, Pascual, \& Fernández-Díaz, 1999; Cara, Moyano, Gander, \& Yúfera, 2007). Estas investigaciones han dado como resultado la elaboración de dietas con gran potencial y las que, de forma resumida, deben cumplir con las características de aceptabilidad, digestibilidad, tamaño de partícula adecuado y una estabilidad en el sistema acuoso.

La aplicación de esta metodología ha sido estudiadas ampliamente, ya sea su resistencia a la descomposición (Muir \& Sutton, 1994) o la incorporación de cubiertas para incrementar su estabilidad (Chu \& Ozkizilcik, 1999). La evaluación de cambios en la calidad nutricional de las proteínas en el proceso de elaboración de dietas (Nordgreen, Yúfera, \& Hamre, 2008) es otro aspecto destacado junto a los materiales de fabricación y su evaluación in vitro (Alarcón, Moyano, \& Díaz, 1999; Cara et al., 2007). Otro aspecto útil de estas dietas microencapsuladas es su funcionalidad como vector mediante la incorporación de aditivos que pueden tener diferentes efectos en el organismo receptor (Sirvas-Cornejo, Latchford, \& Jones, 2007).

Es así que al observar la gran variedad de metodologías y la amplia versatilidad de dichas micropartículas, podemos entrever que éstas, podrían mejorar el manejo productivo en larvas de $A$. tropicus, incrementar la eficiencia de la producción y optimizar las actividades relacionadas con su cultivo comercial y repoblación. 
Por tanto, el objetivo del presente trabajo es evaluar los efectos en crecimiento y supervivencia de diferentes dietas microencapsuladas para el cultivo de larvas de pejelagarto.

\section{MATERIALES Y MÉTODOS}

Con el fin de encontrar un punto de partida en la fabricación de microdietas para el pejelagarto, se compararon dos métodos de fabricación de microcápsulas. La técnica de encapsulación mediante secado por aspersión (Pedroza-Islas, Duirán-Rodríguez, \& TrejoMartínez, 1999) y el encapsulado por gelificación iónica (Rosas-Ledesma, León-Rubio, Alarcón, Moriñigo, \& Balebona, 2012)

\section{Técnica de encapsulación mediante} secado por aspersión: Nutricionalmente se emplearon dos fórmulas previamente probadas, una con base en la harina de pescado (DP) y otra de pollo+cerdo Renderers (Re), ambas propuestas por Frías-Quintana et al. (2010). Para la preparación de la dieta seca, los ingredientes se pesaron según la formulación descrita en el cuadro $1 \mathrm{y}$ fueron mezclados mediante una batidora de rotación marca BATHAMMEX ${ }^{\mathrm{MR}}$ modelo 178716. A la premezcla, se le incorporó posteriormente los ingredientes líquidos (aceite de pescado, lecitina de soya y agua) hasta presentarse una masa compactada. Ésta se colocó en un molino para carne (TORREY ${ }^{\mathrm{MR}} \mathrm{M}-22 \mathrm{R} 1$ Monterrey N.L., México) para dar forma a los pellets con una matriz de $4.5 \mathrm{~mm}$ de diámetro (ACERLOT, INOX). Se secaron en una estufa marca CORIAT ${ }^{\circledR}$ HC-35-D, D.F. México, a una temperatura constante de $40{ }^{\circ} \mathrm{C}$ en un periodo de 24 a $48 \mathrm{hr}$. Posteriormente, se pulverizaron los pellets mediante un mini molino KRUPS ${ }^{M R}$ para, inmediatamente después, fueron cribadas mediante un tamiz eléctrico marca LEESON ${ }^{\mathrm{MR}}$ modelo RX-812 a través de una criba de 500 micras obteniendo un tamaño de partícula homogéneo. Las dietas fueron almacenadas a $4{ }^{\circ} \mathrm{C}$ hasta momento de su encapsulación.

Una vez obtenidas las dietas, éstas se incorporaron en una proporción 1:1 (200 g dieta: $200 \mathrm{~g}$ ligante), utilizándose un $60 \%(120$ g) de
Goma arábiga (GA) Gomas Naturales ${ }^{\circledR}$, S.A de C.V. México y de Suero de leche (WIP) BIO$\mathrm{PRO}^{\mathrm{TM}}$ (DAVISCO, Foods International, Inc. USA), el $40 \%$ (80 g) como ligantes y disueltos en agua destilada $(466.5 \mathrm{ml})$ por separado y agitándose con un mezclador de laboratorio (SILVERSON L4R-T Illinois, USA). Una vez disueltos la GA y WIP se mezclaron juntas a 4000 revoluciones por minuto (rpm) durante 5 min para formar la emulsión y posteriormente se la añadió la respectiva dieta. Una vez obtenidas las emulsiones se sometieron a un secado por aspersión mediante el secador atomizador Mobile Minor (NIRO ATOMIZER Copenhagen, Denmark). La dispersión de la solución fue a una velocidad de alimentación de muestra de $25 \mathrm{ml} / \mathrm{min}$ empleando una bomba peristáltica (MASTERFLEX ${ }^{\circledR}$, Cole-Parmer Instrument Co. Modelo No. 7520-35 Chicago Illinois), $1.20 \mathrm{rpm}, 2.8$ de presión de fuerza de aire (bar) y una temperatura de entrada de aire de 155 ${ }^{\circ} \mathrm{C}$ y de salida de $78{ }^{\circ} \mathrm{C}$. Una vez obtenido el producto se introdujeron en bolsas $\left(\right.$ Ziploc $\left.^{\circledR}\right)$, con cierre hermético de polietileno y colocadas bajo refrigeración hasta su posterior uso.

Técnica de encapsulación por gelificación iónica: Las dietas microencapsuladas (DME) fueron proporcionadas por el Departamento de Biología Aplicada de la Universidad de Almería, España. La metodología que utilizaron está basada en la técnica descrita por Rosas-Ledesma et al. (2012). Se prepararon dos dietas, Nannochloropsis gaditana $(\mathrm{Ng})$ y el preparado enzimático (PE) con pancreatina, cuyos ingredientes se muestra en el cuadro 1. Previamente a la preparación de las mezclas, todas las harinas se pulverizaron y se cribaron mediante un tamiz de $0.067 \mathrm{~mm}$ para conseguir que los ingredientes estuviesen constituidos por partículas con un diámetro homogéneo. Para la elaboración de las DME se procedió de la siguiente manera: Se preparó una emulsión con los componentes lipídicos (la lecitina de soja se disolvió en $40 \mathrm{ml}$ de agua, seguidamente se añadió el aceite de pescado y el preparado de n-3 HUFAS). micronutrientes se disolvieron en $10 \mathrm{ml}$ de agua destilada antes de ser 
CUADRO 1

Composición de las dietas experimentales usadas para la alimentación de larvas de A. tropicus

TABLE 1

Composition of experimental diets used for larval feeding of $A$. tropicus

\begin{tabular}{|c|c|c|c|c|c|}
\hline Ingredientes & $\mathrm{DP}(\mathrm{g})$ & $\operatorname{Re}(\mathrm{g})$ & Ingredientes & $\mathrm{Ng}(\mathrm{g})$ & $\mathrm{PE}(\mathrm{g})$ \\
\hline Harina de sardina ${ }^{a}$ & 489.5 & - & Harina algal (Nannochloropsis gaditana) & 141.0 & - \\
\hline Harina de pollo ${ }^{\mathrm{a}}$ & - & 419.9 & Preparado enzimático ${ }^{3}$ & - & 3.0 \\
\hline Harina de cerdo ${ }^{\mathrm{a}}$ & - & 117.4 & Hidrolizado de pescado ${ }^{2}$ & 48.0 & 48.0 \\
\hline Pasta de soya ${ }^{a}$ & 200.0 & 200.0 & Harina de pescado ${ }^{1}$ & 561.0 & 653.0 \\
\hline Aceite de sardina ${ }^{\mathrm{a}}$ & 69.1 & 30.9 & Harina de calamar & 49.0 & 49.0 \\
\hline Hidrolizado de pescado ${ }^{c}$ & 100.0 & 100.0 & Concentrado de soya & 25.0 & 25.0 \\
\hline Lecitina de soya ${ }^{\mathrm{d}}$ & 36.0 & 36.0 & Aceite de pescado & 5.0 & 5.0 \\
\hline Harina cabeza de camarón ${ }^{\mathrm{a}}$ & 30.0 & 30.0 & Preparado de HUFAS n-3 & 14.0 & 14.0 \\
\hline Harina sangre de res ${ }^{\mathrm{a}}$ & 20.0 & 20.0 & Lecitina de soya & 19.0 & 19.0 \\
\hline Grenetina $^{\mathrm{e}}$ & 20.0 & 20.0 & Maltodextrina & 57.0 & 106.0 \\
\hline Premezcla de vitaminas ${ }^{f}$ & 10.0 & 10.0 & Carboximetil celulosa & 3.0 & 3.0 \\
\hline Premezcla de minerales ${ }^{\mathrm{f}}$ & 5.0 & 5.0 & Cloruro de colina & 8.0 & 8.0 \\
\hline Vitamina $C^{g}$ & 0.8 & 0.8 & Vitaminas y minerales & 19.0 & 19.0 \\
\hline \multirow[t]{3}{*}{ Harina de sorgo ${ }^{b}$} & 9.6 & 8.6 & Goma guar & 19.0 & 19.0 \\
\hline & & & Alginato & 14.0 & 14.0 \\
\hline & & & Vitamina $\mathrm{C}$ & 19.0 & 19.0 \\
\hline Composición química (\%) & \multicolumn{5}{|c|}{ Composición química (\%) } \\
\hline Energía (cal/g) & $5569.2 \pm 37.4$ & $5239.9 \pm 17.0$ & Proteína & $31.24 \pm 0.18$ & $41.09 \pm 0.22$ \\
\hline Proteína & $51.5 \pm 0.2$ & $53.6 \pm 0.3$ & Humedad & $2.01 \pm 0.1$ & $3.25 \pm 0.2$ \\
\hline Lípidos & $18.9 \pm 0.1$ & $13.9 \pm 0.1$ & *Perfil de ácidos grasos: & & \\
\hline Fibra & $1.0 \pm 0.1$ & $1.1 \pm 0.2$ & MA, 14:00 & $3.82 \pm 0.06$ & $3.81 \pm 1.84$ \\
\hline Ceniza & $16.5 \pm 0.1$ & $14.8 \pm 0.1$ & PA, 16:00 & $19.37 \pm 0.33$ & $16.43 \pm 9.00$ \\
\hline ELN & 12.1 & 16.5 & $16: \ln 7$ & $7.81 \pm 0.11$ & $4.76 \pm 0.06$ \\
\hline \multirow[t]{12}{*}{ Humedad } & $3.4 \pm 0.1$ & $5.6 \pm 0.2$ & SA, 18:00 & $4.02 \pm 0.05$ & $4.09 \pm 1.91$ \\
\hline & & & OA, $18: \ln 9$ & $9.26 \pm 0.13$ & $8.26 \pm 0.09$ \\
\hline & & & $18: \ln 7$ & $2.16 \pm 0.04$ & $2.44 \pm 0.03$ \\
\hline & & & LA, $18: 2 n 6$ & $10.18 \pm 0.11$ & $7.36 \pm 0.10$ \\
\hline & & & LNA, 18:3n3 & $1.22 \pm 0.04$ & $1,01 \pm 0.03$ \\
\hline & & & $18: 4 \mathrm{n} 3$ & $0.52 \pm 0.00$ & $1.12 \pm 0.01$ \\
\hline & & & ARA, $20: 4 n 6$ & $1.31 \pm 0.03$ & $0.79 \pm 0.05$ \\
\hline & & & EPA, 20:5n3 & $7.73 \pm 0.11$ & $8.57 \pm 0.14$ \\
\hline & & & $20: \ln 9$ & $0.95 \pm 0.03$ & $0.87 \pm 0.01$ \\
\hline & & & $22: \ln 9$ & $0.20 \pm 0.29$ & - \\
\hline & & & $22: 5 \mathrm{n} 3$ & $0.53 \pm 0.74$ & $0.73 \pm 0.52$ \\
\hline & & & DHA, 22:6n3 & $7.85 \pm 0.16$ & $11.54 \pm 0.17$ \\
\hline
\end{tabular}

Dieta de pescado (DP), dieta Renderers (Re), dieta Nannochloropsis gaditana (Ng) y dieta de preparado enzimático (PE). aProteínas marinas y agropecuarias S.A. de C.V., Guadalajara, Jalisco, ${ }^{\mathrm{b}}$ GALMEX Comercializadora de Insumos Agrícolas S.A. de C.V., Villahermosa, Tabasco, México, 'FERPAC, dPronat Ultra, Mérida, Yucatán, México, e'D'gari, Productos alimenticios y dietéticos relámpago, S.A. de C.V., Tlalpan, México D.F., fPedregal (para trucha Silver Cup), Toluca, Edo. Mex. México, ${ }^{g}$ ROVIMIX ${ }^{\circledR}$ C-EC (Roche) agente activo de $35 \% .{ }^{1}$ LT-94, ${ }^{2}$ CPSP90, ${ }^{3}$ Pancreatina Sigma-Aldrich ${ }^{\circledR}$. $*$ Perfil de ácidos grasos de las cápsulas (valores expresados en \% sobre el total de ácidos grasos analizados). Los valores son la media \pm desviación estándar.

Fish diet (DP), Renderers diet (Re), Nannochloropsis gaditana diet (Ng) and Enzymatic preparation diet (PE). ${ }^{\text {PProteínas }}$ marinas y agropecuarias S.A. de C.V., Guadalajara, Jalisco, ${ }^{b}$ GALMEX Comercializadora de Insumos Agrícolas S.A. de C.V., Villahermosa, Tabasco, México, ${ }^{\mathrm{C}} \mathrm{FERPAC}$, ${ }^{\mathrm{P}}$ ronat Ultra, Mérida, Yucatán, México, ${ }^{\mathrm{e}} \mathrm{D}$ 'gari, Productos alimenticios y dietéticos relámpago, S.A. de C.V., Tlalpan, México D.F., fPedregal (for trout Silver Cup), Toluca, Edo. Mex. México, gROVIMIX ${ }^{\circledR}$ C-EC (Roche) active agent 35\%. ${ }^{1}$ LT-94, ${ }^{2}$ CPSP90, ${ }^{3}$ Pancreatin Sigma-Aldrich ${ }^{\circledR}$. *Fatty acid profile of the capsules (values expressed in \% over the total fatty acids analyzed). Values are represents as average \pm standard deviation. 
incorporados a la mezcla, a continuación se añadió la mezcla de harinas a $650 \mathrm{ml}$ de agua destilada y se dejó mezclar (BATHAMMEX ${ }^{\mathrm{MR}}$ modelo 178716) durante 5 min. Posteriormente se incorporó en la mezcla la solución con los micronutrientes, y pasados otros $5 \mathrm{~min}$ de agitación, se adicionó la emulsión lipídica sobre el conjunto y se dejó mezclar durante $10 \mathrm{~min}$. Después de este tiempo, la mezcla se añadió lentamente sobre $800 \mathrm{ml}$ de una solución de alginato de sodio al $1.5 \%$ que se mantuvo en baño a temperatura de incubación de $40{ }^{\circ} \mathrm{C}$ y en agitación continúa. Todo el producto se colocó en el frasco presurizado del equipo de encapsulación, y se procedió a la elaboración de los alimentos mediante el encapsulador B-390 BÜCHI, pulverizando la mezcla a través de una boquilla con diámetro de salida de 0.3 $\mathrm{mm}$ sobre una solución gelificante $(500 \mathrm{ml}$ de cloruro cálcico al $1 \%$ en un recipiente de 30 $\times 20 \times 8 \mathrm{~cm} \mathrm{a} 4{ }^{\circ} \mathrm{C}$ ), a una altura $15 \mathrm{~cm}$ y en continua agitación. Una vez elaboradas las cápsulas, estás fueron lavadas con agua destilada dos veces y finalmente liofilizadas. En el caso de las microcápsulas PE, la incorporación de la solución de enzimas, se realizó justo antes de proceder a la gelificación (a efectos de reducir la proteólisis sobres los propios ingredientes de la dieta). La preparación de la solución enzimática se obtuvo del sometimiento a ultrasonido por 10 segundos cada uno a $4{ }^{\circ} \mathrm{C}$ de 3 $\mathrm{g}$ de pancreatina suspendida en $10 \mathrm{ml}$ de agua destilada. La mezcla se centrifugó a $16000 \mathrm{~g}$ por 15 min y se recuperó el sobrenadante que se utilizó como preparado enzimático.

Tratamiento control: El tratamiento control consistió en suministrar una dieta con base en nauplios de Artemia (Na) Biogrow, PROAQUA $^{\circledR}$. La composición proximal química de la dieta Na utilizada en la alimentación larval se muestra en el cuadro 2 .

Obtención del material biológico (Atractosteus tropicus): Los embriones de $A$. tropicus se obtuvieron a partir de desoves inducidos de un lote de reproductores (hembra de $3.5 \mathrm{~kg}$ de peso promedio y 3 machos de $1.5 \mathrm{~kg}$ de peso promedio) suministrado por el Laboratorio de Acuicultura Tropical de la División Académica de Ciencias Biológicas, Universidad Juárez Autónoma de Tabasco (DACBiol-UJAT). Una vez realizado el desove y la fecundación (16 horas post-inducción), se retiraron los reproductores manteniendo los huevos hasta su eclosión, momento en el cual los eleuteroembriones se colocaron en un sistema de recirculación con reservorio de 15001 que funciona como sedimentador de sólidos y filtro biológico, además de una bomba centrífuga de $3 / 4$ HP (Jacuzzi, JWPA5D-230A, Delavan WI, USA), con su respectivo filtro de arena sílica (STA-RITE, S166T, Delavan WI, USA) y termostato de titanio (PSA ${ }^{\mathrm{MR}}$ modelo R9ce371).

\section{Diseño experimental y alimentación lar-} varia: Para esta investigación se diseñó un experimento de una vía simple completamente aleatorio con cuatro tratamientos experimentales y un control, los cuales se evaluaron por cuadruplicado tomando como factor diferentes tipos de dietas experimentales, estas fueron: i) microcápsulas con base en harina de Nannochloropsis gaditana $(\mathrm{Ng})$, ii) microcápsulas elaboradas con preparado enzimático (PE) pancreatina SIGMA-ALDRICH ${ }^{\circledR}$, iii) microcápsulas con base en harina de pescado (DP), iv) microcápsulas con base en una combinación de harina de cerdo y pollo (Re) y el control v) dieta control con base en nauplios de Artemia (Na) Biogrow, PROAQUA ${ }^{\circledR}$. Para este experimento las larvas (450 ejemplares de $0.032 \pm 0.004 \mathrm{~g}$ ), se distribuyeron en 15 tanques cónicos de fibra de vidrio con capacidad de 10 1, acoplados al

CUADRO 2

Composición química de los nauplios de Artemia (Na)

TABLE 2

Artemia nauplii (Na) chemical composition

\begin{tabular}{lc}
$\quad$ Ingredientes & $\mathrm{Na}(\%)$ \\
Proteína & 70.2 \\
Grasa & 20.8 \\
Fibra cruda & 2 \\
Ceniza & 6.1 \\
Sum $\omega-3$ HUFA & $>11.0 \mathrm{mg} / \mathrm{g}$ \\
\hline
\end{tabular}


sistema de recirculación previamente descrito, sembrando 30 larvas por unidad experimental. El esquema de alimentación inicio a partir de la absorción de vitelo (DAV), correspondiendo al $7^{\circ}$ día post fertilización (DPF), el cual fue considerado el punto inicial del experimento (Día 0). En los tratamientos experimentales, en primer término, se suministró alimento vivo con base en nauplios de Artemia durante cinco días (0-5 DAV), después se les proporcionaron cinco días más, de co-alimentación con base en nauplios de Artemia más las DME (en los tratamientos experimentales) y a partir del día $10 \mathrm{AV}$ se les proporcionó únicamente las DME (Fig. 1). La pauta de alimentación diaria fue de cuatro veces al día (8:00, 12:00, 16:00 y 20:00 h) tanto para los tratamientos experimentales como para el tratamiento control con nauplios de Artemia (Márquez et al., 2006). La calidad del agua del sistema de recirculación se monitoreó diariamente, registrándose valores promedio en oxígeno de $3.19 \pm 0.52 \mathrm{mg} / \mathrm{l}$ con temperatura de $30.46 \pm 1.1^{\circ} \mathrm{C}$, y un $\mathrm{pH}$ de $7.8 \pm$ $0.3 \mathrm{y}$ semanalmente se registraron las concentraciones de amonio con valores de $0.15 \pm 0.04$ $\mathrm{mg} / \mathrm{l}$, nitritos de $62.67 \pm 5.32 \mathrm{mg} / \mathrm{l}$ y nitratos con $27.24 \pm 2.35 \mathrm{mg} / \mathrm{l}$.

Evaluación de supervivencia y crecimiento: El experimento tuvo una duración total de 20 días a partir del día 0 AV hasta el día
$20 \mathrm{AV}$. El crecimiento fue cuantificado determinando el incremento en peso húmedo y la longitud total de las larvas. La toma de muestras para evaluar el crecimiento se llevó a cabo por la mañana antes de proporcionar el alimento, para lo cual cada larva fue pesada utilizando una balanza digital (precisión $\pm 0.01 \mathrm{~g}$ ) y medida con un vernier digital (precisión $\pm 0.1 \mathrm{~mm}$ ).

Supervivencia: Al final del experimento se determinó la supervivencia (S) como el porcentaje de organismos vivos durante el tiempo del experimento por medio del conteo del total de los peces: $\mathrm{S}=(\mathrm{Nf} / \mathrm{Ni}) \times 100$, donde $\mathrm{Ni}=$ Número inicial de organismos, $\mathrm{Nf}=$ Número final de organismos.

Índices de crecimiento: A partir de los datos de crecimiento de las larvas, se calcularon los siguientes índices: La tasa específica de crecimiento (TEC): TEC $=\left[\left(\operatorname{Ln} \mathrm{P}_{\mathrm{f}}-\operatorname{Ln} \mathrm{P}_{\mathrm{i}}\right) / \mathrm{t}\right] \times$ 100 , donde $\operatorname{Ln} \mathrm{P}_{\mathrm{i}}=$ Logaritmo natural del peso promedio inicial $(\mathrm{g}), \operatorname{Ln} \mathrm{P}_{\mathrm{f}}=$ Logaritmo natural del peso promedio final y $t$ es el tiempo en días. El Factor de conversión alimenticio (FCA): $\mathrm{FCA}=\mathrm{Pa} / \mathrm{Pg}$, donde $\mathrm{Pa}=$ Peso del alimento consumido total $(\mathrm{g})$ y $\mathrm{Pg}=$ Ganancia en peso fresco del pez $(\mathrm{g})$.

Estructura y forma de las microcápsulas: Cada una de las DME se colocaron en

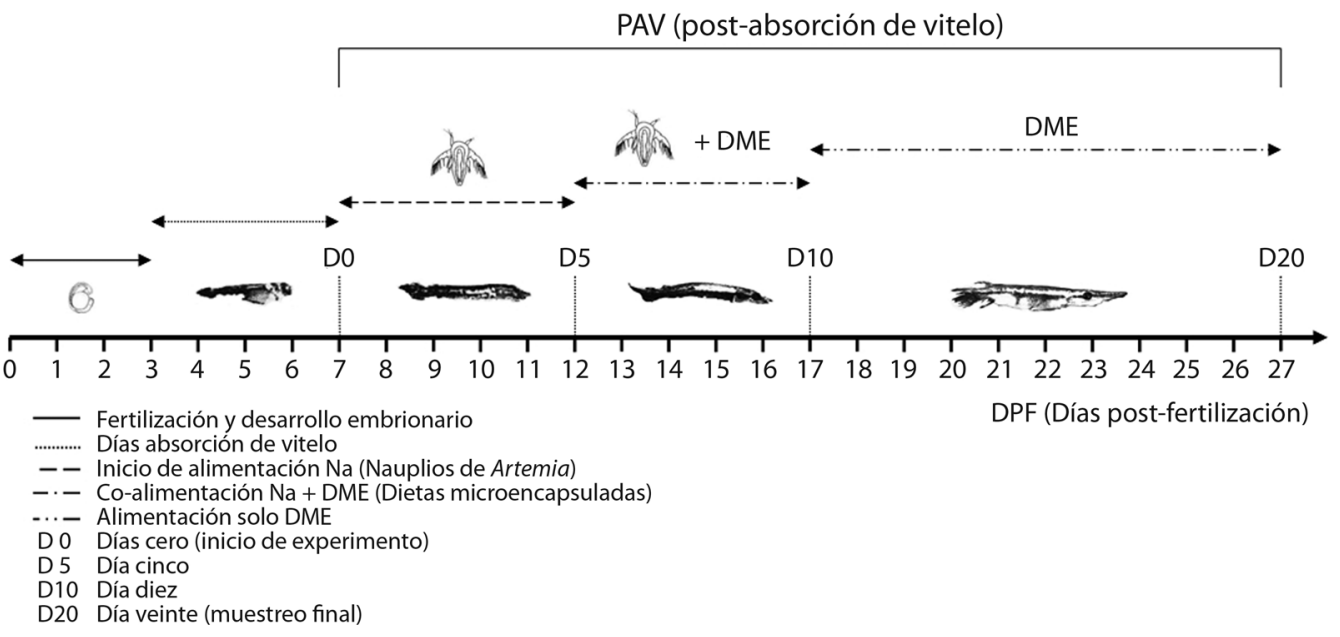

Fig. 1. Alimentación durante el experimento. / Fig. 1. Feeding schedule provided during the experiment. 
porta muestras SEM, utilizando una cinta adhesiva de doble cara (Ted Pella, Redding, CA), la morfología de las partículas fueron observadas a alto vacío por el microscopio electrónico (SEM VEGA LM, TESCAN USA, Inc.), a $20.00 \mathrm{kV}$. Las micrografías representadas fueron seleccionadas para su presentación.

Dureza de partícula de las microcápsulas: La dureza de las microcápsulas se evaluó con una prueba de compresión de $3 \mathrm{~mm}$ sobre cada dieta, con el equipo TA.XT. Plus. Texture Analyzer ${ }^{\circledR}$, con el programa Exponent Stablemicro systems versión 5.1.2.0.

Tamaño de las microcápsulas: Las dietas DP y Re se evaluó por microscopia electrónica (SEM VEGA LM, TESCAN USA, Inc.) y en las dietas $\mathrm{Ng}$ y $\mathrm{PE}$ fue determinado con un medidor Malvern serie 2600 (Malvern Instruments, Malvern Works, UK).

Para el análisis estadístico los datos de peso y longitud total se sometieron a pruebas de normalidad Kolmogorov-Smirnov (K-S) y de homoscedasticidad de Levine. Cumplido este postulado, se aplicó un análisis de varianza de una vía (ANDEVA) seguido de una prueba de Tukey para detectar las diferencias entre los tratamientos. En todos los casos se consideraron diferencias significativas cuando los niveles de probabilidad de las pruebas empleadas fueron iguales o inferiores al $95 \%$. A los datos de supervivencia, e índices de crecimiento de larvas al final del experimento se les realizaron análisis no paramétricos de Kruskal-Wallis seguido de la prueba de Nemenyi para detectar las diferencias entre los tratamientos. Los datos obtenidos fueron evaluados empleando el programa estadístico STATGRAPHICS Plus 5.1 ${ }^{\mathrm{TM}}$ (Statistical Graphics Corp.) y el análisis gráfico de los datos se realizó empleando el programa SIGMA PLOT $11.0^{\mathrm{TM}}$.

\section{RESULTADOS}

Los datos de crecimiento durante todo el periodo experimental se resumen en la (Cuadro 3). Tras un inicio similar en todos los tratamientos $(\mathrm{P}>0.05)$, las diferencias significativas se mostraron a partir del día $10 \mathrm{PAV}$ $(\mathrm{P}<0.05)$, donde las larvas alimentadas con la dieta Na presentaron el peso promedio más alto $(0.12 \pm 0.02 \mathrm{~g})$ y un crecimiento en longitud superior $(3.25 \pm 0.31 \mathrm{~cm})$ con respecto al resto de los tratamientos experimentales. Las larvas

CUADRO 3

Peso húmedo (promedio $\pm \mathrm{DE}$ ) y longitud total (promedio $\pm \mathrm{DE}$ ) de larvas A. tropicus alimentadas con diferentes dietas

TABLE 3

Wet weight (average $\pm \mathrm{SD}$ ) and total length (average $\pm \mathrm{SD}$ ) of $A$. tropicus larvae fed with different experimental diets

\begin{tabular}{ccccccc}
\multirow{2}{*}{ Tratamientos } & \multicolumn{2}{c}{ Día 5 PAV } & \multicolumn{2}{c}{ Día 10 PAV } & \multicolumn{2}{c}{ Día 20 PAV } \\
\cline { 2 - 6 } & Peso $(\mathrm{g})$ & Talla $(\mathrm{cm})$ & Peso $(\mathrm{g})$ & Talla $(\mathrm{cm})$ & Peso $(\mathrm{g})$ & Talla $(\mathrm{cm})$ \\
$\mathrm{Na}$ & $0.05 \pm 0.01^{\mathrm{a}}$ & $1.92 \pm 0.08^{\mathrm{a}}$ & $0.12 \pm 0.02^{\mathrm{a}}$ & $3.25 \pm 0.31^{\mathrm{a}}$ & $0.19 \pm 0.04^{\mathrm{a}}$ & $3.93 \pm 0.56^{\mathrm{a}}$ \\
$\mathrm{Re}$ & $0.06 \pm 0.01^{\mathrm{a}}$ & $1.87 \pm 0.09^{\mathrm{a}}$ & $0.09 \pm 0.01^{\mathrm{b}}$ & $3.00 \pm 0.18^{\mathrm{b}}$ & $0.09 \pm 0.01^{\mathrm{b}}$ & $3.30 \pm 0.52^{\mathrm{b}}$ \\
$\mathrm{DP}$ & $0.06 \pm 0.01^{\mathrm{a}}$ & $1.94 \pm 0.03^{\mathrm{a}}$ & $0.08 \pm 0.01^{\mathrm{b}}$ & $2.91 \pm 0.13^{\mathrm{b}}$ & $0.07 \pm 0.02^{\mathrm{b}}$ & $2.99 \pm 0.64^{\mathrm{b}}$ \\
$\mathrm{PE}$ & $0.06 \pm 0.01^{\mathrm{a}}$ & $1.94 \pm 0.05^{\mathrm{a}}$ & $0.09 \pm 0.01^{\mathrm{b}}$ & $2.90 \pm 0.18^{\mathrm{b}}$ & $0.08 \pm 0.02^{\mathrm{b}}$ & $3.12 \pm 0.47^{\mathrm{bc}}$ \\
$\mathrm{Ng}$ & $0.06 \pm 0.01^{\mathrm{a}}$ & $1.83 \pm 0.15^{\mathrm{a}}$ & $0.08 \pm 0.01^{\mathrm{b}}$ & $2.91 \pm 0.15^{\mathrm{b}}$ & $0.06 \pm 0.01^{\mathrm{b}}$ & $2.85 \pm 0.48^{\mathrm{c}}$ \\
\hline
\end{tabular}

Días 5, 10 y 20 post-absorción de vitelo (PAV): Dieta de pescado (DP), dieta Renderers (Re), dieta de Nannochloropsis gaditana $(\mathrm{Ng})$, dieta con preparado enzimático (PE) y nauplios de Artemia (Na). Promedios con superíndices diferentes en la columna indican diferencias significativas $(\mathrm{P}<0.05)$.

Days 5, 10 and 20 post yolk absorption (PAV): Fish diet (DP), Renderers diet (Re), Nannochloropsis gaditana diet (Ng) and Enzymatic preparation diet (PE). Average with different superscript letters in the columns show statistical differences $(\mathrm{P}<0.05)$. 
alimentadas con las DME, en el día 10 de muestreo, no presentaron diferencias entre los tratamientos ni en peso (Re con $0.09 \pm 0.01 \mathrm{~g}$, $\mathrm{PE}$ con $0.09 \pm 0.01 \mathrm{~g}, \mathrm{Ng}$ con $0.08 \pm 0.01 \mathrm{~g}$ y $\mathrm{DP}$ con $0.08 \pm 0.01 \mathrm{~g}$ ) ni en longitud (Re con $3.00 \pm 0.18 \mathrm{~cm}, \mathrm{DP}$ con $2.91 \pm 0.13 \mathrm{~cm}, \mathrm{Ng}$ con $2.91 \pm 0.15 \mathrm{~cm}$ y Pe con $2.90 \pm 0.18 \mathrm{~cm}) . \mathrm{Al}$ igual que en el punto de muestreo anterior, al final del experimento (,día $20 \mathrm{AV}$ ) se observó que larvas alimentadas con el alimento vivo (tratamiento $\mathrm{Na}$ ) fueron las más grandes en longitud y peso $(\mathrm{P}=0.001)$, alcanzando una talla de $3.93 \pm 0.56 \mathrm{~cm}$ y un peso de $0.19 \pm 0.04 \mathrm{~g}$, estadísticamente diferentes que al resto de los tratamientos. En este momento del experimento tampoco presentó diferencias significativas en peso para las larvas alimentadas con la DME, aunque los valores de los tratamientos Re (0.09 $\pm 0.01 \mathrm{~g})$ y $\mathrm{PE}(0.08 \pm 0.02 \mathrm{~g})$ fueron levemente superiores a los de los tratamientos DP (0.07 $\pm 0.15 \mathrm{~g})$ y $\mathrm{Ng}(0.06 \pm 0.01 \mathrm{~g})$. En el caso de la longitud, para el día $20 \mathrm{AV}$, los resultados no sufrieron modificaciones al comparar con punto de muestreo anterior (10 AV). Respecto a la supervivencia, en la dieta $\mathrm{Na}(82.5 \%)$ se obtuvo el valor más alto, mientras que las larvas alimentadas con las DME fueron menores estadísticamente respecto al tratamiento anterior (Fig. 2). Los tratamiento Ng y PE (20.0\% y $19.2 \%$ ) fueron estadísticamente superiores (P $=0.001)$ a las alimentadas con los tratamientos DP y Re, que mostraron los valores de supervivencia más bajos comparados al resto de los tratamientos (5 y $2.5 \%$ respectivamente). Por tanto, observamos que los tratamientos alimentados con encapsulados mediante gelificación iónica presentaron una mayor supervivencia, con diferencias significativas $(\mathrm{P}=0.001)$, respecto a las larvas alimentadas con tratamientos encapsulados con secado por aspersión.

En el caso de la tasa específica de crecimiento (TEC) se evidenció diferencias significativas $(\mathrm{P}<0.05)$ del tratamiento $\mathrm{Na}(8.83$ $\%$ / día) con respecto al resto de tratamientos. Las larvas alimentadas con las dietas PE, Ng y DP fueron estadísticamente menores respecto al tratamiento anterior, pero iguales entre ellas (4.42, 3.49 y $3.12 \%$ / día). Finalmente, los peces que tuvieron la TEC más baja fueron los alimentados con la $\operatorname{Re}(2.40 \%$ / día). En el caso del factor de conversión alimenticia (FCA) las larvas alimentadas con la dieta $\mathrm{Na}$ presentaron el menor valor con $10.28 \pm 0.22$ y junto con la dieta $\operatorname{Re}(15.84 \pm 10.14)$ fueron iguales estadísticamente mientras que, un segundo grupo de dietas la PE y DP $(36.40 \pm 8.95$ y 30.12 $\pm 12.27)$, fueron estadísticamente iguales con $\mathrm{Ng}(50.32 \pm 9.00)$ pero esta última distinta de $\mathrm{Na}(\mathrm{P}<0.05)$ (Cuadro 4). También se pudo observar, que los valores obtenidos para los tratamientos con dietas diseñadas elaboradas por gelificación iónica, son más uniformes con respectos a los obtenidos mediante secado por aspersión.

Las micrografías mediante microscopía electrónica, obtenidas de microencapsulación de secado por aspersión (dietas Re y DP), muestran partículas con una geometría redondeada irregulares y de varios tamaños. Las partículas mostraron una superficie arrugada

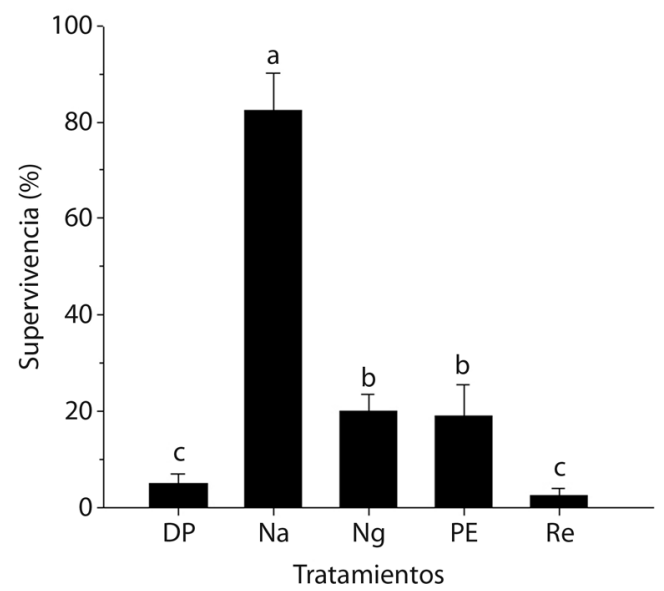

Fig. 2. Supervivencia de larvas de A. tropicus al día 20 postabsorción de vitelo con diferentes dietas: Dieta de pescado (DP), Nauplios de Artemia (Na), dieta de Nannochloropsis gaditana $(\mathrm{Ng})$, dieta de preparado enzimático $(\mathrm{PE})$, dieta Renderers $(\mathrm{Re})$. Los superíndices indican igualdad estadísticamente entre tratamientos $(\mathrm{N}=30)$.

Fig. 2. Survival of A. tropicus larvae at 20 days post yolk absorption feed different diets. Fish diet (DP), Artemia nauplio $(\mathrm{Na})$, Nannochloropsis gaditana diet $(\mathrm{Ng})$, Enzymatic preparation diet (PE), Renderers diet (Re). Superscript values indicate equality between treatments $(\mathrm{N}=30)$. 
CUADRO 4

Índice de crecimiento de larvas de $A$. tropicus (promedio $\pm \mathrm{DE}$ ), alimentadas con las diferentes dietas

TABLE 4

Growth index of $A$. tropicus (average $\pm \mathrm{SD}$ ) larvae feed with different diets

\begin{tabular}{ccc} 
Tratamientos & \multicolumn{2}{c}{ Índices } \\
& TEC $(\% /$ día $)$ & FCA \\
$\mathrm{Na}$ & $8.83 \pm 0.08^{\mathrm{a}}$ & $10.28 \pm 0.22^{\mathrm{a}}$ \\
$\mathrm{Re}$ & $2.40 \pm 2.86^{\mathrm{b}}$ & $15.84 \pm 10.14^{\mathrm{a}}$ \\
$\mathrm{DP}$ & $3.12 \pm 2.21^{\mathrm{b}}$ & $30.12 \pm 12.27^{\mathrm{ab}}$ \\
$\mathrm{PE}$ & $4.42 \pm 0.86^{\mathrm{b}}$ & $36.40 \pm 8.95^{\mathrm{ab}}$ \\
$\mathrm{Ng}$ & $3.49 \pm 0.51^{\mathrm{b}}$ & $50.32 \pm 9.00^{\mathrm{b}}$ \\
\hline
\end{tabular}

Dieta de pescado (DP), dieta Renderers (Re), dieta de Nannochloropsis gaditana $(\mathrm{Ng})$, dieta de preparado enzimático (PE) y nauplios de Artemia (Na). Superíndices diferentes indican diferencias estadísticas $(\mathrm{P}<0.05)$. Tasa específica de crecimiento (TEC): ((ln peso final $\ln$ peso inicial) $/ \mathrm{t}) \times 100$. Factor de conversión alimenticia $(\mathrm{FCA})$ : Alimento total consumido, g/Ganancia en peso, g).

Fish diet (DP), Renderers diet (Re), Nannochloropsis gaditana diet $(\mathrm{Ng})$ and Enzymatic preparation diet (PE). Average with different superscript letters in the columns show statistical differences $(\mathrm{P}<0.05)$. Specific growth rate (TEC): ((ln final weight $\ln$ initial weight $) / t) \times 100$. Feed conversion rate (FCA): (Total consume food, g/weight gain, g).

y lisa, no observándose grietas o poros en la superficie externa (Fig. 3A y Fig. 3B). En las dietas diseñadas por gelificación iónica $(\mathrm{Ng}$ y PE), se muestran forma redondeadas irregulares con superficies ásperas y porosas, observándose las partículas de las harinas englobadas en la matriz de alginato. Todas las partículas con la fase interna (material que es cubierto), distribuida en una matriz de pared, manteniendo el material activo disperso en la matriz polimérica (Fig. 3C y Fig. 3D).

En el caso de la dureza observada en las micropartículas, los resultados se resumen en el cuadro 5, donde se detectó que los valores obtenidos de las microcápsulas obtenidas mediante secado por aspersión obtuvieron valores inferiores en comparación a las microcápsulas fabricadas mediante gelificación iónica, aunque no presentaron diferencias significativas entre los tratamientos. Finalmente, las medidas
CUADRO 5

Valores de dureza de las dietas microencapsuladas (DME), usadas en la alimentación de larvas de A. tropicus

TABLE 5

Hardness values of the diets used for feeding A. tropicus larvae

\begin{tabular}{cc} 
DME & $\begin{array}{c}\text { Dureza } \\
(\mathrm{kg} / \mathrm{f})\end{array}$ \\
$\mathrm{Re}$ & $0.05 \pm 0.01^{\mathrm{b}}$ \\
$\mathrm{DP}$ & $0.08 \pm 0.01^{\mathrm{b}}$ \\
$\mathrm{PE}$ & $0.27 \pm 0.26^{\mathrm{a}}$ \\
$\mathrm{Ng}$ & $0.66 \pm 0.27^{\mathrm{a}}$ \\
\hline
\end{tabular}

Dieta de pescado (DP), dieta Renderers (Re), dieta de Nannochloropsis gaditana $(\mathrm{Ng})$ y dieta de preparado enzimático (PE). Promedios con superíndices diferentes en la columna indican diferencias significativas $(\mathrm{P}<0.05)$.

Fish diet (DP), Renderers diet (Re), Nannochloropsis gaditana diet $(\mathrm{Ng})$ and Enzymatic preparation diet (PE). Average with different superscript letters in the columns show statistical differences $(\mathrm{P}<0.05)$.

volumétricas obtenidas de los tamaños de las partículas de las dietas DP y Re fueron en promedio de $19.11 \pm 1.01 \mu \mathrm{m}$ y las dietas $\mathrm{Ng}$ y $\mathrm{PE}$ fueron de $485.0 \pm 25.0 \mu \mathrm{m}$.

\section{DISCUSIÓN}

Los resultados obtenidos en el presente estudio, tanto en crecimiento como supervivencia, indican una diferencia entre las larvas alimentadas con alimento vivo $(\mathrm{Na})$ y el resto de tratamientos (Re, DP, PE y Ng). Esto es un resultado esperado, ya que, en el cultivo de esta especie y en esta etapa de desarrollo, la eliminación del alimento vivo durante el cultivo desencadena este suceso, al igual que sucede en otras especies, como es el caso descrito por Person-Le Ruyet, Alexander, Thébaud, \& Mugnier (1993) al trabajar con larvas de lubina Europea (Dicentrarchus labrax, Linnaeus 1758). En el caso de sustituciones mediante microdietas comerciales, se observó un retardo en el desarrollo larval (Cañavate \& FernándezDíaz, 1999; Ribeiro et al., 2005; Fletcher et al., 2007) y se aprecia este mismo efecto en ensayos con uso de micropartículas, como es 

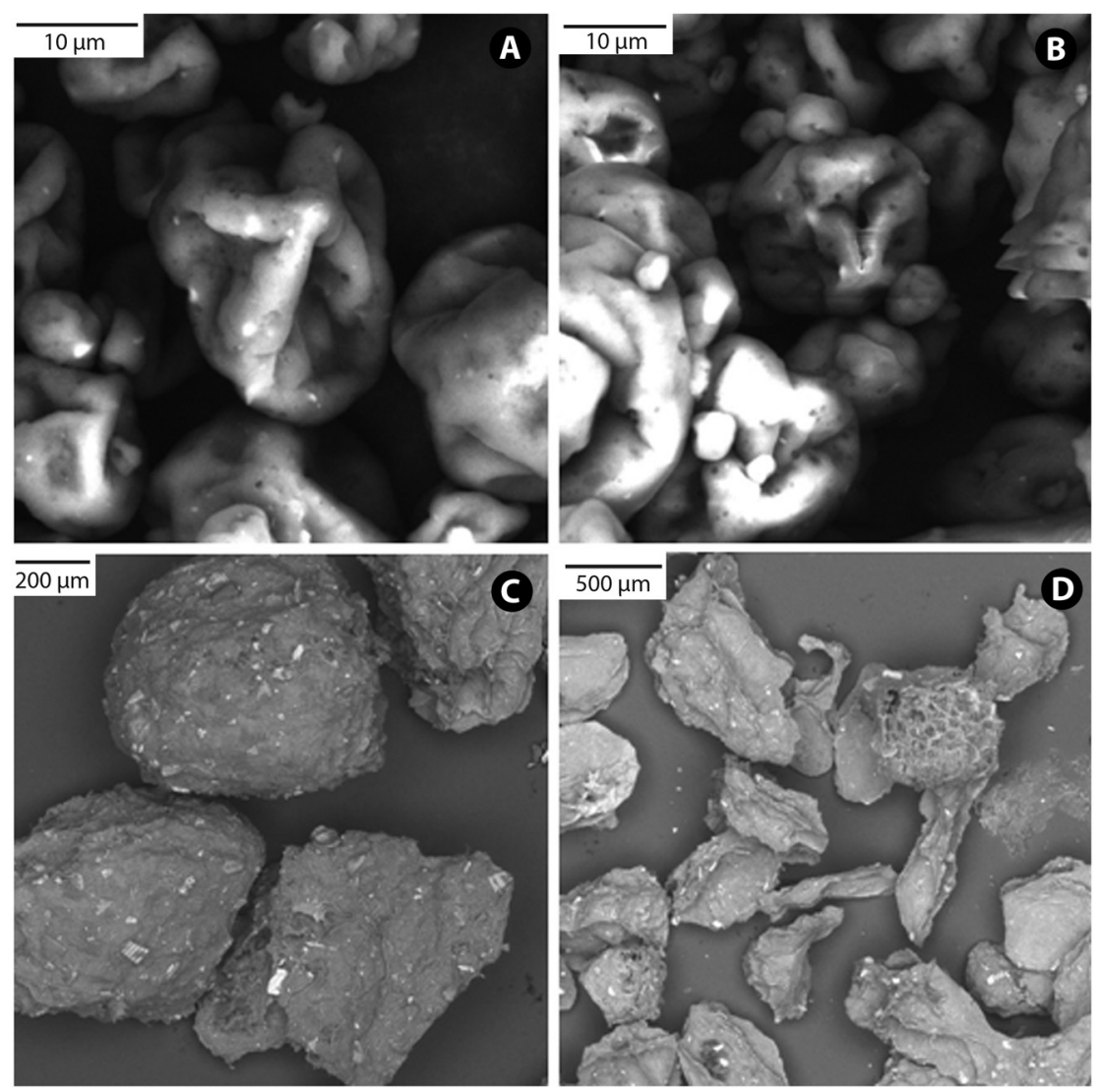

Fig. 3. A-D. Topografía externa de las dietas microencapsuladas para larvas de A. tropicus. Dieta Renderers (A), dieta de pescado (B), dieta de preparado enzimático (C) y dieta de Nannochloropsis gaditana (D). A-B) Escala $=10 \mu \mathrm{m}$; C) Escala $=200 \mu \mathrm{m} ; \mathrm{D})$ Escala $=500 \mu \mathrm{m}$.

Fig. 3. A-D. External topography of microencapsulated diets for A. tropicus larvae. Renderers diet (A), fish diet (B), enzymatic preparation diet (C) and Nannochloropsis gaditana diet (D). A-B) Scale $=10 \mu \mathrm{m}$; C) Scale $=200 \mu \mathrm{m}$; D) Scale $=500 \mu \mathrm{m}$.

el caso observado en Pagrus major (Takeuchi, 2001) o cabrilla arenera (Paralabrax maculatofasciatus, Steindachner 1868) (García, 2006) al evaluar dietas microencapsuladas realizadas por gelificación interna. Como se pudo observar, la alimentación con alimento vivo suele inducir mayor crecimiento que las dietas inertes en las primeras fases de desarrollo de las larvas, sin embargo, a pesar de la idoneidad del alimento vivo para las etapas tempranas de los cultivos larvales, en sus fases posteriores, y a diferencia de lo que ocurre con las dietas inertes, la administración exclusiva de Artemia parece no cubrir totalmente las necesidades nutricionales de los peces y este hecho puede limitar el potencial de crecimiento en el cultivo larvario de algunas especies. Es por ello que se aconseja una etapa de co-alimentación mediante la cual, los individuos se adecuen a la dieta inerte (Person-Le Ruyet et al., 1993; Fernández-Díaz \& Yúfera, 1997; Rosenlund, Stoss, \& Talbot, 1997).

En general, se suele utilizar dos tipos de estrategias para adaptar las larvas. En primer lugar, está el denominado destete brusco, en el que se sustituye, de un día para otro, el alimento vivo por el alimento de transición. Por otro lado, el destete en co-alimentación en el 
que, antes de esta sustitución, se ofrece la dieta inerte junto con nauplios de Artemia durante un número variable de días, dependiendo tanto de la especie como del manejo. Para este experimento y dado que el objetivo era observar diferencias lo antes posible, se seleccionó un destete relativamente brusco para esta especie, ya que usualmente, éste se realiza durante un periodo de 15 días (Márquez et al., 2006). Basándonos en este objetivo, los datos obtenidos por el tratamiento control $(\mathrm{Na})$ solamente nos sirven para evaluar si el sistema de cultivo funcionó correctamente, ya que un aumento en la mortalidad o un descenso en el crecimiento de dicho tratamiento nos serviría como indicador para detectar posibles problemas durante el desarrollo del experimento.

Al centrarnos en los resultados de crecimiento obtenidos entre los tratamientos experimentales, no se apreciaron diferencias significativas entre ellos, ni en el día $10 \mathrm{ni}$ al finalizar el experimento. El peso y la longitud total prácticamente permanecen constantes los últimos diez días de ensayo. Este efecto posiblemente está relacionado con el periodo de adaptación a la nueva alimentación (Engrola et al., 2007), periodo en el cual las larvas y sus tractos digestivos se adaptan para poder aumentar la biodisponibilidad y absorción de nuevo alimento. Este periodo es variable y depende de la especie por sus características digestivas. Está claro que en nuestro caso, las larvas aún estaban en el proceso de adaptación ya que la energía y el alimento bioasimilado de los diferentes tratamientos no era suficiente, hasta ese momento, para que el crecimiento fuese mayor. Durante el periodo de adaptación al nuevo alimento, los individuos dedican mayor cantidad de energía a la función digestiva que a la de crecimiento. Este, apenas es apreciable en el caso de los tratamientos experimentales, pero pueden indicar que, en el momento final del ensayo, aún no se han acabado de adaptar o que el alimento bioasimilado no era suficiente para que los individuos continúen con las funciones de crecimiento, a pesar que para esa edad ya cuentan con el sistema digestivo totalmente desarrollado (Frías-Quintana et al., 2015).
En el caso de la supervivencia de las larvas entre las metodologías implementadas, se puede observar que las cápsulas obtenidas por gelificación interna dieron mejores resultados que las que se realizaron por medio de la metodología de encapsulación secado y aspersión. Sin embargo, estos valores son bastante bajos con respecto al control. Al observar trabajos que se realizaron con microcápsulas en otras especies, se puede comprobar que los resultados bajos en supervivencia son usuales. En el caso de Clack (2006), reportó bajas supervivencias en larvas del gobio (Asterropteryx semipunctata, Rüppell, 1830) probando diferentes dietas microencapsuladas con promedios que fueron del 6 a $8 \%$. De igual forma, García (2006), evaluó alimentación con dietas microencapsuladas en larvas de P. maculatofasciatus, quien indicó que la supervivencia de las larvas fue entre 0.28 y $0.68 \%$. En este mismos sentido, Menossi et al. (2012), tras evaluar el crecimiento y desarrollo del tracto digestivo en larvas de pacu (Piaractus mesopotamicus, Holmberg 1887) con una dieta experimental microencapsulada producida por gelificación interna, reportan que las larvas no llegaron a sobrevivir al finalizar el experimento (23 días).

Es así que varios factores pueden hacer que la mortalidad aumente considerablemente cuando se realiza el cambio de alimento vivo a inerte, los cuales se pueden resumir en que los individuos no obtienen los nutrientes necesarios para realizar sus funciones básicas. En el caso de ser ingerido el alimento, la causa podría ser debida a una posible deficiencia nutricional en el diseño de las dietas o por la pérdida de estos nutrientes por la lixiviación de los compuestos solubles antes de ser ingeridos (Langdon, 2003). Este último es un punto clave, ya que las larvas de peces carnívoros poseen una elevada demanda de nutrientes altamente solubles y de bajo peso molecular, principalmente aminoácidos libres, que están presentes de manera natural en el alimento vivo (Dabrowski, 1979; Lauff \& Hoffer, 1984; Kuz'mina, 2015) y que cubren una parte importante de sus necesidades metabólicas. Por lo tanto, si se reduce considerablemente el aporte de estos requerimientos, 
las larvas disminuirán su crecimiento e incluso podrían llegar a morir. También el método de encapsulación puede influir en la composición final del alimento, por ejemplo, las propiedades fisicoquímicas de los productos obtenidos por secado por aspersión dependen de muchos variables del proceso como, las características del líquido alimentado al sistema (viscosidad, tamaño de partícula, velocidad de flujo) y del aire de secado (temperatura y presión), así como el tipo de atomizador, por lo que es importante la optimización del proceso de secado, con el fin de obtener productos con mejores características sensoriales y nutritivas (Tonon, Brabet, \& Hubinger, 2008).

En el caso de los índices evaluados en el experimento, los valores más bajos en de los tratamientos experimentales con respecto al tratamiento control vienen condicionados a que, en fases tempranas de los cultivos larvarios, la utilización de alimento vivo determina mejores tasas de crecimiento que cuando son alimentadas con dieta inerte (Cañavate \& Fernández-Díaz, 1999; Chang et al., 2006). El valor de la tasa específica de crecimiento (TEC) expresa el incremento porcentual en peso por día a lo largo de todo el periodo experimental y resulta útil para comparar crecimientos en periodos de tiempo relativamente cortos (Ricker, 1958; Engrola et al., 2007) y aunque, en este caso, no se aprecian diferencias significativas, si se puede confirmar que las medias son mayores en los tratamientos con dietas diseñadas por gelificación iónica. Para el Factor de conversión alimenticio (FCA) obtenemos el mismo resultado que en el índice anterior, aunque en este caso, los valores obtenidos están muy influenciados por la diferencia en la supervivencia de los tratamientos, ya que, este es un valor que interviene directamente en la ganancia de peso fresco de los tanques de experimentación y, por tanto, en el valor obtenido al final. Otro dato observado para las larvas alimentadas con las microcápsulas elaboradas mediante secado y aspersión, es la gran dispersión obtenida en sus valores de diámetro con respecto a la otra metodología utilizada. La existencia de esta elevada variabilidad pudo determinar la ausencia de diferencias significativa entre estos tratamientos. Añadido a esto, esa elevada dispersión en los valores puede servir como indicador en estos tratamientos, de un desarrollo anómalo de los individuos (Cara et al., 2007). De esta forma, las larvas alimentadas con microcápsulas realizadas con la misma metodología (secado y aspersión) presentaron diferencias significativas en los índices de calidad del alimento, ni crecimiento de los organismos.

Finalmente, con el fin de buscar una de las posibles causas de las diferencias entre los tratamientos experimentales, se realizó un estudio físico de las partículas, evaluando la morfología, resistencia y el tamaño de partícula. En las micrografías realizadas mediante microscopía electrónica de las microcápsulas obtenidas por secado por aspersión (dietas Re y DP), se muestra una forma común esencialmente debido a los materiales utilizados en la técnica, presentan una superficie arrugada y lisa debido al colapso producido por la pérdida de volumen tras el secado de las micropartículas. En el caso de las dietas diseñadas por gelificación iónica (dieta $\mathrm{Ng}$ y PE), se presenta una estructura semejante a la obtenida por otros autores utilizando este polímero como agente encapsulante (González-Rodríguez, Holgado, Sánchez-Lafuente, Rabasco, \& Fini, 2002; Mladenovska et al., 2007). La forma esférica viene determinada por la interacción entre las propiedades químicas del alginato al gelificar por acción de los iones $\mathrm{Ca}^{+2}$ y las condiciones mecánicas establecidas (rozamiento y velocidad de agitación).

Para las medidas volumétricas obtenidas de los tamaños de las partículas, en el caso de Ng y PE no se aleja mucho del observado por anteriores trabajos en la fabricación de micropartículas para larvas marinas, como el de Yúfera, Pascual y Fernández-Díaz (1999) utilizando una técnica de polimerización interfacial de parte de la proteína dietaria, donde las partículas obtenidas cubrían un intervalo de 50-300 $\mu \mathrm{m}$, la media fue $120 \mu \mathrm{m}$. Más recientemente, Langdon (2003), utilizó la pulverización de lípidos para encapsular riboflavina 
obteniendo un rango de tamaño de 45-106 $\mu \mathrm{m}$, rango algo inferior al obtenido en el actual trabajo. Este tamaño de partícula es similar al del alimento vivo (Na) de alrededor de los 500 $\mu \mathrm{m}$. Sin embargo, el tamaño obtenido mediante el secado por aspersión (DP y Re) obtuvieron un tamaño medio cercano a $20 \mu \mathrm{m}$, un valor bastante bajo para al tamaño de la boca de la larva de pejelagarto que mide alrededor de 250 $\mu \mathrm{m}$ (Frías-Quintana et al., 2016).

El tamaño de las microcápsulas es un elemento determinante en la ingesta por parte de las larvas de peces, ya que partículas excesivamente pequeñas pueden ser no detectadas, mientras que partículas grandes son difíciles o imposibles de ingerir y digerir (Walford, Lim, \& Lam, 1991). Añadido a esto, los peces carnívoros, como predadores, deben seleccionar las presas con el tamaño de partícula lo suficientemente grande para compensar el gasto energético invertido en su captura (PedrozaIslas, Macías-Bravo, \& Vernon-Carter, 2002). Por tanto, una partícula de aproximadamente $20 \mu \mathrm{m}$ en este experimento, posiblemente fuese la causa de que las dietas obtenidas mediante el secado por aspersión mostrasen un resultado inferior en supervivencia con respecto a las realizadas mediante encapsulación por gelificación iónica. Sin embargo, las condiciones establecidas para la producción de las partículas fueron las propuestas por Pedroza-Islas, Alvarez-Ramírez y Vernon-Carter (2000) las cuales pueden ser fácilmente modificables para adaptarlas a la consecución de tamaños diferentes de partícula.

Respecto a la estabilidad de las dietas, PE y Ng en el agua mostraron ser más estables que las dietas DP y Re, las cuales, al entrar en contacto con el agua, se disolvían enturbiándola considerablemente, debido a las propiedades funcionales de diferentes hidrocoloides (goma arábiga) y algunas proteínas (como suero de leche), que fueron utilizadas como sustancias ligantes o materiales formadores de pared de las microcápsulas (Pedroza-Islas et al., 2000). La selección de estas sustancias, así como en sus proporciones, son de suma relevancia ya que asigna a las dietas evaluadas características imprescindibles como la solubilidad, flotabilidad y velocidad de sedimentación, los cuales pueden ser factores determinantes para mejorar las condiciones de asimilación, supervivencia y crecimiento de los organismos (Fernández-Díaz, Kopecka, Cañavate, Sarasquete, $\&$ Solé, 2006).

En conclusión, el presente estudio expone varios factores que pueden contribuir a los resultados obtenidos para estos dos tipos de microcápsulas: baja digestión de la dieta, una composición nutricional inadecuada para asegurar el desarrollo larval, un sistema digestivo no totalmente maduro para hidrolizar $\mathrm{y}$ asimilar los nutrientes presentes en la dieta y la estabilidad de dichas partículas en el agua. No obstante, esta información puede ser un punto de partida para mejorar la calidad de microcápsulas como un vehículo para el ensayo de las dietas en los estudios nutricionales utilizando larvas de esta especie de sumo interés en el sureste de México. Es así que las larvas alimentadas con microcápsulas obtenidas mediante la técnica de secado por aspersión obtuvieron tuvieron resultados similares en crecimiento a las larvas alimentadas con las microcápsulas elaboradas con la técnica de gelificación iónica; sin embargo, la supervivencia obtenida fue mayor significativamente en el segundo caso. Se considera que la baja estabilidad de las micropartículas obtenidas mediante la técnica de secado por aspersión y el tamaño de partícula puede ser determinante para la baja supervivencia que presentan las larvas de A. tropicus alimentadas con estas dietas.

\section{AGRADECIMIENTOS}

El autor expresa su agradecimiento al Consejo Nacional de Ciencia y Tecnología (CONACYT), por el apoyo brindado a través de la convocatoria de becas nacionales 2010, № 290604. También a la Secretaría de Educación Superior por el apoyo económico dentro del Programa para el Desarrollo Profesional Docente (PRODEP) en su versión Apoyo a la Incorporación de Nuevos Profesores de Tiempo Completo. Al Programa de Fomento a la 
Investigación y Consolidación de los Cuerpos Académicos (PFICA)-UJAT, y al programa de becas ECOES (Espacio Común de Educación Superior) Santander Universidades en México, por el apoyo financiero otorgado durante la realización de la estancia de investigación. De igual forma a Miguel Ángel Rayas, por su asistencia técnica en la fabricación de las dietas microencapsuladas en la Universidad Iberoamericana. Y finalmente, a Silvia Arias García de la DACBiol-UJAT, por su asistencia técnica en las micrografías tomadas para este estudio.

\section{RESUMEN}

El pejelagarto es una especie importante para la acuicultura en el sureste de México. Se han realizado varios estudios sobre nutrición y fisiología digestiva; sin embargo, el uso de microcápsulas para la alimentación de larvas que permitan mejorar el crecimiento y la supervivencia no ha sido realizado. En este sentido, se evaluaron cuatro alimentos microencapsulados en el crecimiento y supervivencia de larvas de pejelagarto (Atractosteus tropicus). Los tratamientos consistieron en cuatro dietas experimentales y un control: 1) Microcápsula con base en harina de pescado (DP), 2) Microcápsula con base en una combinación de harina de cerdo y pollo (Re), 3) Microcápsula con base en Nannochloropsis gaditana (Ng), 4) Microcápsula con base en un preparado enzimático, pancreatina (PE) el tratamiento control 5) Nauplios de Artemia (Na). Los resultados de las dietas indican que las larvas alimentadas con Nauplios (Na) tuvieron el mayor crecimiento y supervivencia (3.93 $\mathrm{cm}, 0.19 \mathrm{~g} \mathrm{y} 82 \%$ respectivamente). Mientras que en el caso de las larvas alimentadas con las dietas microencapsuladas, los mejores valores de supervivencia se observaron con las dietas Nannochloropsis gaditana $(\mathrm{Ng})$ y preparado enzimático (PE) (20.0 y 19.2\% respectivamente). Nuestros resultados demuestran que el uso de microencapsulados para la alimentación de larvas de A. tropicus es factible, aunque se requieren más investigaciones para optimizar su diseño y elaboración para mejorar el crecimiento y supervivencia de los organismos.

Palabras clave: acuicultura; dietas microencapsuladas; larvas, crecimiento; supervivencia.

\section{REFERENCIAS}

Alarcón, F. J., Moyano, F. J., \& Díaz, M. (1999). Optimization of the protein fraction of microcapsules used in feeding of marine fish larvae using in vitro digestibility techniques. Aquaculture Nutrition, 5, 107-113.
Álvarez-González, C. A., Márquez-Couturier, G., Contreras-Sánchez, W. M., \& Rodríguez-Valencia, W. (2007). Estrategia para el uso sustentable de los recursos pesqueros en Boca de Chilapa, Reserva de la Biosfera Pantanos de Centla, Tabasco: Establecimiento de una planta de producción de peces nativos, pejelagarto, tenguayaca y castarrica. En G. Halffter, S. Guevara, \& A. Melic (Eds.), Monografias 3ercer Milenio. La cultura de la diversidad biológica. (Vol. 6, pp. 197-205). Zaragoza, España: SEA, CONABIO, CONANP, CONACYT, INECOL, UNESCO-MaB \& Ministerio del Medio Ambiente-Gobierno de España. M3M, GORFI S.A.

Cahu, C., \& Zambonino-Infante, J. L. (2001). Substitution of live food by formulated diets in marine fish larvae. Aquaculture, 200(1-2), 161-180.

Cañavate, J. P., \& Fernández-Díaz, C. (1999). Influence of co-feeding larvae with live and inert diets on weaning the sole Solea senegalensis onto comercial dry feeds. Aquaculture, 174, 255-263.

Cara, J. B., Moyano, F. J., Gander, B., \& Yúfera, M. (2007). Development of novel casein-protamine based microparticles for early feeding of fish larvae: in vitro evaluation. Journal of Microencapsulation, 24(6), 505-514.

Chang, Q., Liang, M. Q., Wang, J. L., Chen, S. Q., Zhang, X. M., \& Liu, X. D. (2006). Influence of larval co-feeding with live and inert diets on weaning the tongue sole Cynoglossus semilaevis. Aquaculture Nutrition, 12(2), 135-139.

Chu, F. E., \& Ozkizilcik, S. (1999). Acceptability of complex microencapsulated diets by striped bass (Morone saxatilis) larvae. Journal of Experimental Marine Biology and Ecology, 237, 1-9.

Clack, B. W. (2006). Development of microparticulate feeds and methods to improve acceptability of artificial diets by blue spotted goby larvae (Asterropteryx semipunctata) (Master's thesis). Oregon State University, Oregon, USA.

Dabrowski, K. (1979). The role of proteolitic enzymes in fish digestion. In E. Styczunska-Jurewivcsk, T. Jaspers, \& E. Persoone (Eds.), Cultivation of Fish Fry and its Live Food (Vol. 4, pp. 107-126). Belgium: European Mariculture Society.

Engrola, S., Conceição, L. E. C., Dias, L., Pereira, R., Ribeiro, L., \& Dinis, M. T. (2007). Improving weaning strategies for Senegalese sole: effects of body weight and digestive capacity. Aquaculture Research, 38, 696-707.

Fernández-Díaz, C., Kopecka, J., Cañavate, J. P., Sarasquete, C., \& Solé, M. (2006). Variations on development and stress defences in Solea senegalensis larvae fed on live and microencapsulated diets. Aquaculture, 251, 573-584. 
Fernández-Díaz, C., \& Yúfera, M. (1997). Detecting growth in gilthead seabream, Sparus aurata L., larvae fed microcapsules. Aquaculture, 153, 93-102.

Fletcher, R. C. Jr, Roy, W., Davie, A., Taylor, J., Robertson, D., \& Migaud, H. (2007). Evaluation of new micro particulate for early weaning of Atlantic cod (Gadus morhua): Implication on larval performances and tank hygiene. Aquaculture, 263, 35-51.

Frías-Quintana, C. A., Álvarez-González, C. A., \& Márquez-Couturier, G. (2010). Diseño de microdietas para el larvicultivo de pejelagarto Atractosteus tropicus, Gill 1863. Universidad y Ciencia, 26(2), 265-282.

Frías-Quintana, C. A., Marquez-Couturier, G., AlvarezGonzalez, C. A., Tovar-Ramirez, D., Nolasco-Soria, H., Galaviz-Espinosa, M. A., ... Gisbert, E. (2015). Development of digestive tract and enzyme activities during the early ontogeny of the tropical gar Atractosteus tropicus. Fish Physiology and Biochemistry, 41(5), 1-17.

Frías-Quintana, C. A., Domínguez-Lorenzo, J., ÁlvarezGonzález, C. A., Tovar-Ramírez, D., \& Martínez-García, R. (2016). Using cornstarch in microparticulate diets for larvicultured tropical gar (Atractosteus tropicus). Fish Physiology and Biochemistry, 42, 517-528.

García, R. E. (2006). Uso de dietas microencapsuladas para la alimentación de larvas de la Cabrilla Arenera Paralabrax maculatofasciatus (Tesis de Maestría). Instituto Politécnico Nacional, Centro Interdisciplinario de Ciencias Marina. La Paz, Baja California Sur, México.

González-Rodríguez, M. L., Holgado, M. A., SánchezLafuente, C., Rabasco, A. M., \& Fini A. (2002). Alginate/chitosan particulate systems for sodium diclofenac release. International Journal of Pharmaceutics, 232, 225-234.

Guerrero-Zárate, R., Alvarez-González, C. A., OlveraNovoa, M. A., Perales-García, N., Frías-Quintana, C. A., Martínez-García, R., \& Contreras-Sánchez, W. M. (2014). Partial characterization of digestive proteases in tropical gar Atractosteus tropicus juveniles. Fish Physiology and Biochemistry, 40, 1021-1029.

Hart, P. R., \& Purser, G. J. (1996). Weaning of hatcheryreared greenback flounder (Rhombosolea tapirina Gunther) from live to artificial diets: Effects of age and duration of the changeover period. Aquaculture, $145,171-181$.

Kuz'mina, V. V. (2015). The role of proteases of food objects and enteral microbiota in nutritive and thermal adaptations of the digestive system in fishes. Journal of Evolutionary Biochemistry and Physiology, 51(3), 179-189.
Langdon, C. J. (2003). Microparticle types for delivering nutrients to marine fish larvae. Aquaculture, 227, 259-275.

Langdon, C. J., Levine, D. M., \& Jones, D. A. (1985). Microparticulate feeds for marine suspension-feeders. Journal of Microencapsulation, 2, 1-11.

Lauff, M., \& Hoffer, R. (1984). Proteolitic enzymes in fish development and the importance of dietary enzymes. Aquaculture, 37, 335-346.

Lavens, P., \& Sorgeloos, P. (2000). The history, present status and prospects of the availability of Artemia cyst for aquaculture. Aquaculture, 181, 397-403.

Márquez-Couturier, G., Álvarez-González, C. A., Contreras, W., Hernández, U., Hernández-Franyutti, A. A., ... Goytortua, E. (2006). Avances en la alimentación y nutrición de pejelagarto Atractosteus tropicus. En L. E. Cruz Suárez, D. Ricque Marie, M. Tapia Salazar, M. G. Nieto López, D. A. Villarreal Cabazos, A. C. Puello, \& A. García Ortega (Eds.), Memorias del VIII Simposium Internacional de Nutrición Acuícola (pp. 446-523). Monterrey, Nuevo León, México: UANL.

Márquez-Couturier, G., Váquez-Navarrete, C. J., Contreras-Sánchez, W. M., \& Alvarez-González, C. A. (2015). Acuicultura tropical sustentable: Una estrategia para la producción y conservación del pejelagarto (Atractosteus tropicus) en Tabasco, México. Colección José Narciso Rovirosa (2a Ed. Vol. 3). México: Universidad Juárez Autónoma de Tabasco.

Menossi, O. C., Takata, R., Sánchez-Amaya, I., Mendes de Freitas, T., Yúfera, M., \& Portella, M. C. (2012). Crescimento e estruturas do sistema digestório de larvas de pacu alimentadas com dieta microencapsulada produzida experimentalmente. Revista Brasileira de Zootecnia, 41(1), 1-10.

Mladenovska, K., Raicki, R. S., Janevikb, E. I., Ristoski, T., Plavova M. J., Kavrakovski, Z., Dodov, M. G., \& Goracinova, K. (2007). Colon-specific delivery of 5-aminosalicylic acid from chitosan-Ca-alginate microparticles. International Journal of Pharmaceutics, 342, 124-136.

Muir, P. R., \& Sutton, D. C. (1994). Bacterial degradation of microencapsulated foods used in larval culture. Journal of the World Aquaculture Society, 25(3), 371-378.

Nordgreen, A., Yúfera, M., \& Hamre, K. (2008). Evaluation of changes in nutrient composition during production of cross-linked protein microencapsulated diets for marine fish larvae and suspension feeders. Aquaculture, 285, 159-166.

Pedroza-Islas, R., Duirán-Rodríguez, C., \& Trejo-Martínez, S. (1999). Using biopolymer blends for shrimp feedstuff micro encapsulation II: particle size, morphology 
and microstructure of microcapsules. Food Research International, 32, 167-374.

Pedroza-Islas, R., Alvarez-Ramírez, J., \& Vernon-Carter, E. J. (2000). Using biopolymer blends for shrimp feedstuff micro encapsulation II: dissolution and floatability kinetrics as selection criteria. Food Research International, 33, 19-24.

Pedroza-Islas, R., Macías-Bravo, S., \& Vernon-Carter, E. J. (2002). Oil thermo-oxidative stability and surface oil determination of biopolymer microcapsules. Revista Mexicana de Ingeniería Química, 1, 37-44.

Person-Le Ruyet, J., Alexander, J. C., Thébaud, L., \& Mugnier, C. (1993). Marine fish larvae feeding: formulated diets or live prey. Journal of the World Aquaculture Society, 24, 211-224.

Ricker, W. E. (1958). Handbook of computations for biological statistics of fish populations. Canadian Journal of Fishery and Aquatic Science, 119, 1-300.

Ribeiro, L., Engrola, S. \& Dinis. M. T. (2005). Weaning of senegalense sole (Solea senegalensis) postlarvae to an inert diet with a co-feeding regime. Ciencias Marinas, 31, 327-337.

Rosas-Ledesma, P., León-Rubio, J., Alarcón, F. J., Moriñigo, M. A., \& Balebona, M. C. (2012). Calcium alginate capsules for oral administration of fish probiotic bacteria: assessment of optimal conditions for encapsulation. Aquaculture Research, 43, 106-116.
Rosenlund, G., Stoss, J., \& Talbot, C. (1997). Co-feeding marine fish larvae with inert and live diets. Aquaculture, 155, 183- 191.

Sirvas-Cornejo, S., Latchford, J. W., \& Jones, D. A. (2007). Effect of microencapsulated diets supplemented with genetically modified bacteria on the growth and survival of Fenneropenaeus indicus postlarvae. Aquaculture Nutrition, 13, 10-16.

Takeuchi, T. (2001). A review of feed development for early life stages of marine finfish in Japan. Aquaculture, 200, 203-222.

Tonon, R. V., Brabet, C., \& Hubinger, M. D. (2008). Influence of process conditions on the physicochemical properties of acai (Euterpe oleraceae) powder produced by spray drying. Journal of Food Engineering, 88, 411-418.

Walford, J., Lim, T. M., \& Lam, T. J. (1991). Replacing live food with microencapusulated diets in the rearing of sea bass (Lates calcarifer) larvae: do the larvae ingest and digest protein-membrane microcapsules? Aquaculture, 92, 225-235.

Walker, P. J., \& Mohan, C. V. (2009). Viral disease emergence in shrimp aquaculture: origins, impact and the effectiveness of health management strategies. Reviews in Aquaculture, 1, 125-154.

Yúfera, M., Pascual, E., \& Fernández-Díaz, C. (1999). A highly efficient microencapsulated food for rearing early larvae of marine fish. Aquaculture, 177, 249-256. 